\title{
STUDIES OF TOTAL PULMONARY CAPACITY AND ITS SUB- DIVISIONS. II. CORRELATION WITH PHYSICAL AND RADIOLOGICAL MEASUREMENTS
}

\author{
BY ALBERTO HURTADO ${ }^{1}$ AND WALTER W. FRAY \\ (From the Department of Medicine of the School of Medicine and Dentistry of the \\ University of Rochester and the Medical Clinic and Division of Radiology \\ of the Strong Memorial Hospital, Rochester, N. Y.)
}

(Received for publication April 7, 1933)

In a previous paper (5) we have presented the results of 50 determinations of pulmonary capacity made in an equal number of healthy males. It was demonstrated that the relative capacities (expressed in percentages of the total volume) fluctuated within narrow limits, but that there were wide variations in the absolute figures found for the total volume and its subdivisions. This fact makes rather difficult the recognition of moderate, and perhaps important, deviations in a given case, and also prevents a clear understanding of any alterations in the relative values. Thus a low ratio (Vital capacity/Total volume) $\times 100$ may be caused by either increased residual air, low vital capacity, or a combination of both factors, and the proper interpretation will be obtained only if normal values are available for comparison. To standardize the procedure, it appears to be necessary to find a correlation between the pulmonary capacity and certain bodily characteristics, so that from a knowledge of the latter it may be possible to predict the normal volumes. If we have at our disposal reliable criteria to permit judgment of changes in absolute, as well as in relative pulmonary capacity a clearer. view of the underlying pathological physiology may be obtained. A basis may also be provided for the proper classification and grouping of cases of respiratory inefficiency in which defective alveolar ventilation is an important factor.

Although numerous investigations have been made to correlate the vital capacity to body or chest measurements, there have been very few attempts to correlate these characteristics with the total pulmonary capacity or with any one of its subdivisions, other than vital capacity. Lundsgaard and Van Slyke (7) in 1918 found in a few cases a definite correlation between the total capacity, vital capacity, mid capacity and residual air, and the so-called "chest volume," calculated from the external measurement of the three diameters of the chest obtained at the end of full inspiration and expiration under resting conditions. This investigation was later confirmed by Lundsgaard and Schierbeck (6) who found a similar relationship and also con-

1 Travelling Fellow of the Rockefeller Foundation. 
cluded that the degree of chest expansion (as determined by external measurements) affects the prediction of the corresponding pulmonary capacity. But Binger and Brow (2) could not demonstrate such a correlation of pulmonary capacities, either with the external chest measurements, with the body height, or with the surface area, and suggested that the level of the diaphragm was the determining factor, since a long-chested type of individual with relaxed abdominal walls shows a greater total volume than the broad, deep-chested muscular type. These investigators stated that the measurement of the area of the lung fields on radiographic films gives a fairly satisfactory means for predicting pulmonary capacity in normal individuals, although they did not prove so in the pneumonic patients whom they were then investigating. No data were presented in their communication to support this conclusion. Binger (1), while studying cases of cardiac decompensation, predicted the normal pulmonary capacity by assuming a vital capacity of 2.5 liters per square meter of body surface, and from this the other volumes were calculated on the basis of the rather fixed relative values of the main subdivisions of the total volume.

We have made in our 50 cases a statistical study of the possible correlations of the pulmonary capacities with dimensions of the body and chest, and with radiological measurements. It was also our aim in this study to gain helpful information concerning the comparative value of the methods for the determination of the degree of chest expansion, a factor seldom properly evalulated clinically but undoubtedly of importance in a consideration of respiratory mechanics. To find the influence of the shape of the chest on the different subdivisions of pulmonary capacity was another purpose of the investigation.

\section{METHODS}

The body height and weight were recorded in all cases, and the surface area calculated from the DuBois charts. The following chest measurements were obtained in all subjects (without clothing) in the respiratory positions of full expiration, mid capacity (at the end of a normal expiration), and on full inspiration: (a) Chest circumference-measured at the level of the nipple line, just below the pectoral prominences; (b) Lateral diameter (width), the distance between the midaxillary lines at the level of the nipple; (c) Anteroposterior diameter (depth), the distance from the midsternal line, also at the level of the nipples, to the vertebral column; and (d) Longitudinal diameter (height), a distance from the upper end of the sternum, at the mid-line, to the junction of the body with the xiphoid process of this same bone. A pair of calipers (pelvimeter) was used in making the measurements.

The external "chest volume" in the three respiratory positions was calculated (according to the Lundsgaard and Van Slyke technique) from the product of the diameters at the corresponding positions. 
Radiographs of the chest were obtained at the end of maximum expiration, maximum inspiration, normal expiration and, in most instances, at the end of normal inspiration. These four exposures were obtained on two films in the following manner: one of the films was first exposed at the end of maximum expiration, the exposure time being about threequarters of that in routine radiography of the chest. A brass filter, 0.2 $\mathrm{mm}$. in thickness, was then placed over the chest at the level of the diaphragms, and a second exposure of the same length and character was made on the same film at the end of maximum inspiration. This film, when developed, shows the bony thorax and the diaphragm at both phases of respiration. The object in using the brass filter is to prevent overexposure of the chest, particularly of the diaphragm, during the second portion of the exposure. Much this same effect can be obtained without the use of the brass filter by making the length of exposure at expiration approximately five times that at inspiration. We found it more convenient to use the filter, and at the same time obtained better definition of the upper portion of the thorax on inspiration. The principles of this technique have been explained by Thomas (1931) (8).

It is of the greatest importance that both exposures be made at the proper phase of respiration; i.e., after maximal effort, since the data obtained are used for the prediction of normal pulmonary capacity. We have found it convenient to use a signal (movement of fingers of one of the patient's hands) for timing the exposures

The second film was obtained in a similar manner, varying only the phase of respiration for the exposures to normal expiration and normal inspiration. It is extremely important that the exposure for expiration be made first; reversal of the order results in obliterating the shadow of the diaphragm at expiration.

The films were obtained in the recumbent position. The individual was placed in the prone position on a table, the top of which had been modified to accommodate a tunnel in which the film cassette could be slipped without altering the position of the subject. The target-film distance was six feet. The exposure time was approximately $1 / 20$ second. The kilovoltage was varied according to the thickness of the chest. The milliamperage remained constant at 200 milliamperes.

Films obtained in this manner show the degree of expansion of the thorax and of the excursion of the diaphragm during maximal and quiet respiration. Because of the fact that such films do not impart any idea of the third dimension, lateral films were tried during the early portion of the work in an attempt to define the anteroposterior diameter. The use of these were abandoned because of the difficulty in obtaining two photographic impressions of the upper portion of the chest on the same film.

In determining the size of the chest, two linear dimensions of the chest were used, the transverse diameter and the height of the lung field (above 
the level of the domes of the diaphragm). The transverse diameter was obtained at the level of the 9th interspace posteriorly, the measurement being taken from the inner aspects of the ribs. The height of the lung fields was determined by measuring the vertical distance from the dome of the diaphragm to the plane of the first rib ( $\mathrm{EF}$ expiration and $\mathrm{GH}$ inspiration, Figure 1).

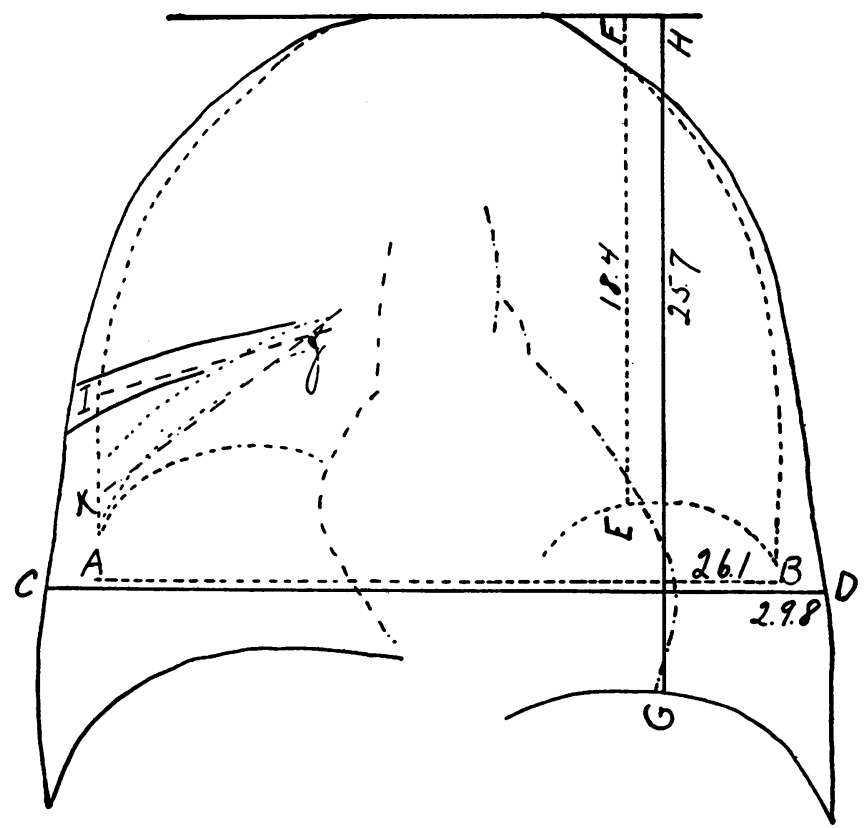

Fig. 1. Outlines of Radiological Film with Double Exposure TechniQue (at Maximum Expiration and Inspiration)

Different measurements taken.

These linear dimensions impart a very imperfect, or at least an incomplete, idea of the variation in chest size. For this reason a planimeter, which recorded areas accurately up to $900 \mathrm{sq}$. cm., was constructed. The integrating wheel of this planimeter was approximately $7.5 \mathrm{~cm}$. in diameter, the tracing arm $50 \mathrm{~cm}$. in length, and the fixed arm $62 \mathrm{~cm}$. This instrument was calibrated by cutting circular grooves in a brass plate with diameters ranging from 10 to $40 \mathrm{~cm}$. The areas enclosed by these grooves were computed. The planimeter was calibrated by comparing the readings on the scale after the point of the tracer arm completed the circle in the individual grooves with the respective areas as computed. A graph was plotted from these determinations.

With this instrument the areas of the lung fields were determined from the films obtained at the end of maximum and of normal expiration and inspiration. The tracer arm was moved along the following course: the 
left axilla, left half of the diaphragm, right half of the diaphragm, right axilla, right apex, and finally swept across the spine to the starting point at the left apex. The cardiac area, including the great vessels, was also obtained separately. The tracings obtained from films of a normal subject are illustrated in Figure 1. The area of the lung fields at maximum expiration was found to be 342 sq. cm., and at maximum inspiration 571 sq. $\mathrm{cm}$. The difference represents the increase in area during maximal respiratory effort. Similarly, mensuration of the film taken at the end of normal expiration and inspiration yields data concerning the difference in area to be used in measuring reserve, complementary and tidal air, etc.

The extent of motion of the ribs was measured by determining the angular displacement of ribs during maximum respiratory effort. The 7 th rib (posterior portion) was usually selected because it could be seen best in a film taken at maximum expiration and inspiration. Lines were drawn representing the direction of the same rib at expiration and inspiration and the angle between them measured. In the normal subject illustrated, this angle (IJK) becomes $22^{\circ}$.

Because of the curved course of the rib, its direction was determined by the slope of the outer two-thirds of its posterior portion.

It was thought that a better approximate value of the size of the chest cavity could be obtained from combined external and radiological measurements. We have multiplied in all cases the area of the lung fields (the area of the heart included) expressed in square centimeters, by the corresponding anteroposterior diameter (depth) of the chest measured externally in centimeters. The result is designated in this paper as the "radiological chest volume."

CORRELATION OF THE PULMONARY CAPACITY WITH PHYSICAL AND RADIOLOGICAL MEASUREMENTS

The correlation of the total capacity and its main subdivisions with body and chest dimensions and with radiological measurements has been summarized in Table I. It is convenient to mention that correlation coefficients are significant only when they exceed the probable error multiplied by three and that correlation is proportionally better as coefficients approach the value of 1 .

In regard to the total capacity, we find that the highest correlation is obtained when the "radiological chest volume" (at maximum inspiration) is used. It is correlated significantly, although in a lesser degree, with the area of lung fields (also at maximum inspiration) and with the body height. There is no useful correlation between the total pulmonary capacity and external chest measurements; the correlation coefficients are either valueless or very low.

The vital capacity is also better correlated with the "radiological chest volume." Its correlation of $+0.7174 \pm 0.0467$ is the highest of the 
TABLE I

Correlation of pulmonary capacities with physical and radiological measurements

\begin{tabular}{|c|c|}
\hline Characteristics correlated & Correlation coefficient \\
\hline Total pulmonary capacity and body weight. & $-0.1267 \pm 0.0944^{*}$ \\
\hline Total pulmonary capacity and body height. & $+0.5509 \pm 0.0661$ \\
\hline Total pulmonary capacity and body surface area. & $+0.1644 \pm 0.0930$ \\
\hline $\begin{array}{l}\text { Total pulmonary capacity and chest circumference (maximum in- } \\
\text { spiration) } \ldots \ldots \ldots \ldots \ldots \ldots \ldots \ldots \ldots \ldots \ldots \ldots \ldots \ldots \ldots \ldots \ldots \ldots \ldots \ldots \ldots \ldots\end{array}$ & $+0.1370 \pm 0.0944$ \\
\hline $\begin{array}{l}\text { Total pulmonary capacity and chest volume }(\text { external) }(\text { maximum } \\
\text { inspiration }) \ldots \ldots \ldots \ldots \ldots \ldots \ldots \ldots \ldots\end{array}$ & $+0.3271 \pm 0.0856$ \\
\hline $\begin{array}{l}\text { Total pulmonary capacity and area of lung fields (maximum inspira- } \\
\text { tion) } \ldots \ldots \ldots\end{array}$ & $+0.5848 \pm 0.0627$ \\
\hline $\begin{array}{l}\text { Total pulmonary capacity and radiological chest volume (maximum } \\
\text { inspiration) } \ldots \ldots \ldots \ldots \ldots \ldots \ldots \ldots \ldots \ldots \ldots \ldots \ldots \ldots \ldots \ldots\end{array}$ & $+0.6366 \pm 0.0566$ \\
\hline
\end{tabular}

Vital capacity and body weight.................... $+0.1377 \pm 0.0930$

Vital capacity and body height ....................... $+0.5452 \pm 0.0667$

Vital capacity and body surface area .................. $+0.2791 \pm 0.0876$

Vital capacity and chest circumference (maximum inspiration).... + $0.1591 \pm 0.0824$

Vital capacity and chest volume (external) (maximum inspiration) $. .+0.3741 \pm 0.0816$

Vital capacity and area of lung fields (maximum inspiration) ...... $+0.6824 \pm 0.0509$

Vital capacity and radiological chest volume (maximum inspiration) $+0.7174 \pm 0.0467$

Mid capacity and chest circumference (mid-position) . . . . . . $\quad-0.2361 \pm 0.0897$

Mid capacity and chest volume (external) (mid-position) . . . . . . $-0.0554 \pm 0.0957$

Mid capacity and area of lung fields (mid-position)............ $+0.5432 \pm 0.0674$

Mid capacity and radiological chest volume (mid-position) ....... $+0.4437 \pm 0.0769$

Residual air and chest circumference (maximum expiration) ...... $-0.0737 \pm 0.0944$

Residual air and chest volume (external) (maximum expiration)... $+0.1065 \pm 0.0937$

Residual air and area of lung fields (maximum expiration)....... + $0.3707 \pm 0.0823$

Residual air and radiological chest volume (maximum expiration) . + $+0.3826 \pm 0.0809$

* Probable error.

series, and consequently will be advantageously taken as the basis for the prediction of the normal pulmonary capacity in a given case. It is interesting to observe the almost valueless correlation between the vital capacity and the body surface area, a rather surprising finding as it has been widely accepted in clinics, following the work of West (9) in 1920. $\mathrm{He}$ found that this volume is better related to body surface area than to any other physical dimension, normal men having a vital capacity of about 2.5 liters per square meter. From the present observations and from previous experience, we think that there are wide variations in this relationship; it is usually found only when there is a normal balance between height and weight, and is not obtained in subjects who are either over or under weight. This has been so frequently observed in various clinics that it has limited the usefulness of the vital capacity determinations on the basis of body surface area, unless marked alterations are found.

The scatter of our fifty observtions around the lines of correlation when the total capacity, the vital capacity and the different bodily thoracic and radiological measurements are compared, may be appreciated from a study of the Figures 2 and 3 . It is plainly evident that the best correlation is 


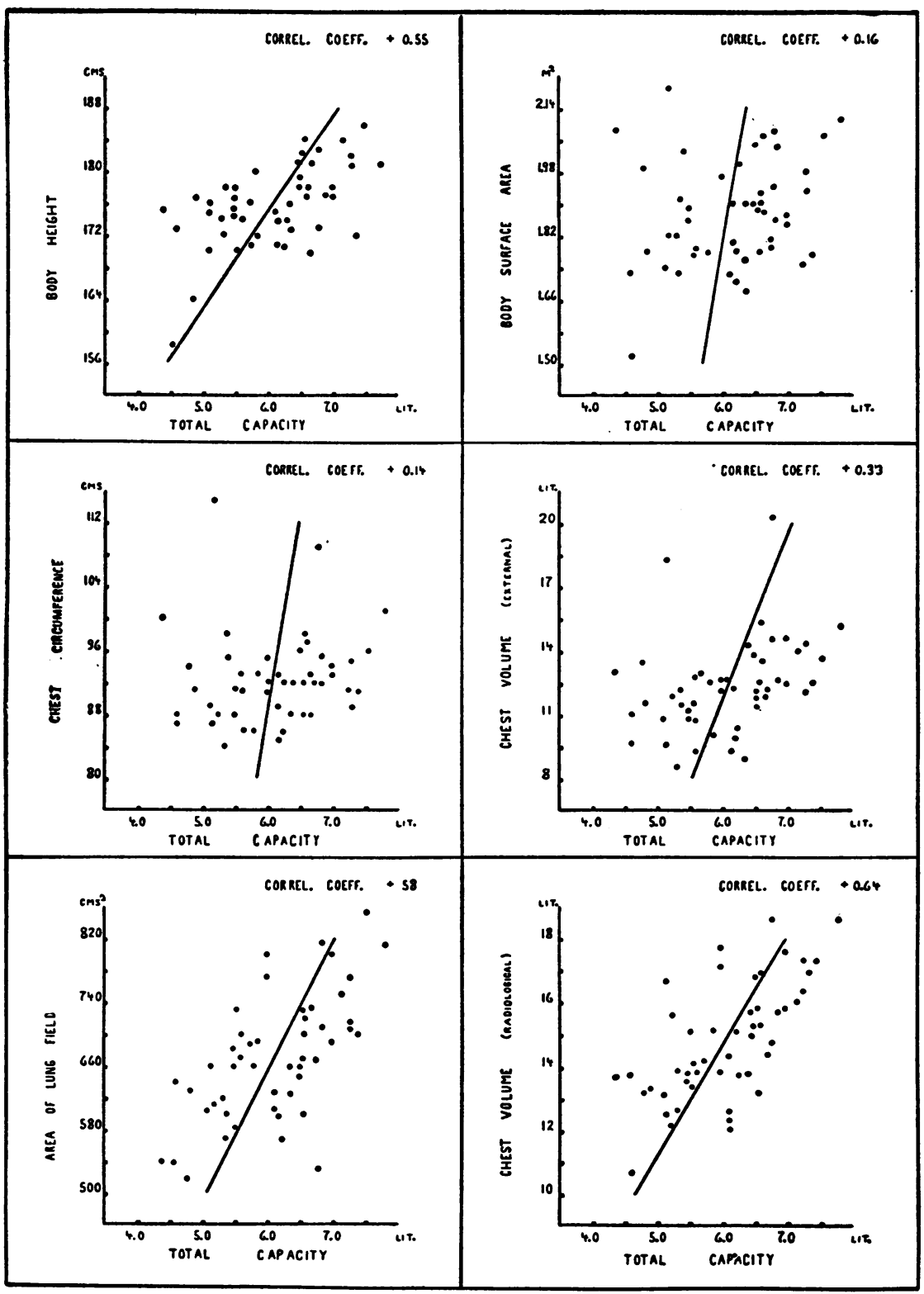

Fig. 2. Correlation between the Total Pulmonary Capacity and Physical and Radiological Measurements

Lines represent ideal correlations (from the regression equations). Dots represent individual observations. 


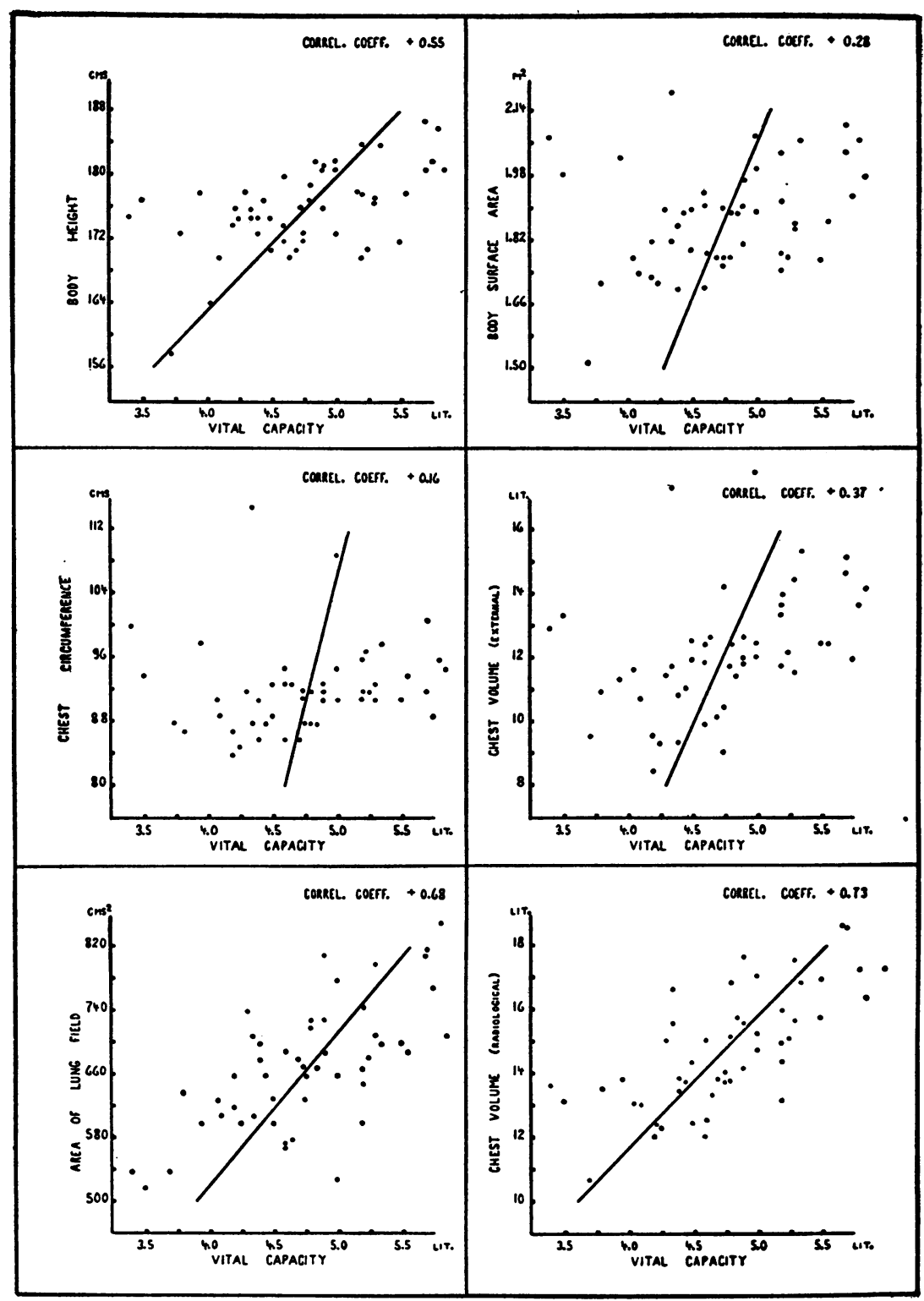

Fig. 3. Correlation between the Vital Capacity and Physical and Radiological Measurements

The lines represent the ideal correlation (as calculated from corresponding regression equations). Dots represent individual observations. 
found in the case of the "radiological volume" and $(a)$ the total capacity (Fig. 2) and (b) the vital capacity (Fig. 3).

When we come to the mid capacity we find a less perfect correlation with radiological data, and a complete lack of relationship with external chest measurements. It is correlated best with the area of lung fields (radiological exposure at the end of a normal expiration), a fact worth taking into account in investigations where this subdivision of total volume is the only one that was determined and where knowing its normal value is desirable. $^{2}$ The residual air is in very low correlation with radiological measurements, and in no correlation with external chest measurements.

From these observations it appears that we have been unable to confirm the early work of Lundsgaard and Van Slyke, and Lundsgaard and Schierbeck in demonstrating a correlation between the total capacity and its main subdivisions with the "chest volume" calculated from the three external diameters of the chest. This conclusion could have been predicted for it is evident that although the lateral and anteroposterior diameters may represent the dimensions of the chest in these planes the measurement of its height is not identical with the length of the sternum, and cannot indicate the level of the diaphragm, which varies widely from and independently of the sternal length. The " chest volume" calculated from these measurements yields consequently a doubtful value of the true volume of the chest cavity. Theoretically, it appeared to be a sounder assumption that multiplying the area of the lung fields measured in radiological films, and the anteroposterior diameter of the chest, determined externally, would secure a value more accurately representative of the true size of the chest cavity. This assumption has been verified, for in this way a better correlation has been found between the volume of the lungs and that of the chest.

\section{PREDICTION OF THE NORMAL CAPACITY OF THE LUNGS}

It has now been shown that in the total series of correlations between the total pulmonary capacity and its components and the physical and radiological measurements, the highest and most significant correlation coefficient has been observed between the vital capacity and the "radiological chest volume." This fact indicates that if the chest volume is known in a given case, the vital capacity may be predicted with a fair degree of accuracy by means of the regression formula derived from the correlation coefficient. $^{3}$ Other fractions of the total capacity may be inferred from the percentage values which the vital capacity, the mid capac-

2 The regression formula derived from the correlation coefficient between the mid capacity volume and the area of lung fields (also at the same respiratory position) is as follows:

Mid capacity (liters) $=\left(\right.$ area of lung fields in $\left.\mathrm{cms}^{2} \times 0.0042\right)+0.33$.

${ }^{3}$ The regression formula is

Vital capacity $($ liters $)=($ radiological chest volume $($ liters $) \times 0.24)+1.22$. 
ity, and the residual air usually constitute of the total volume. The method of calculation in a given example is as follows:

(a) The area of the lung fields at full inspiration and measured on the radiological film is $608 \mathrm{~cm}^{2}$. The external anteroposterior diameter of the chest at the same respiratory position is $27.5 \mathrm{~cm}$. Therefore, the radiological chest volume is $608 \times 27.5=16.72$ liters.

(b) The expected vital capacity is (according to the regression formula $):(16.72 \times 0.24)+1.22=5.23$ liters.

(c) The total pulmonary capacity then is (taking into account that the vital capacity is 78 per cent of the total volume $):(5.23 / 78) \times 100=6.70$ liters.

(d) The residual air is equal to the total volume minus the vital capacity : $6.70-5.23=1.47$ liter.

(e) The mid capacity is (taking into account that this volume is 38 per cent of the total volume $):(6.70 \times 38 / 100)=2.55$ liters.

With the purpose of establishing the normal limits of variability in the values of the pulmonary capacity, we have used this method of calculation in our 50 cases, and the results have been compared graphically with the actual findings. Figure 4 illustrates the calculated and the observed capacities, and demonstrates the striking degree of correspondence which has been found. It appears that a deviation of more than 15 per cent in the observed total volume and vital capacity may be considered significant. In the mid capacity and residual air, since the values are much smaller, the percentage deviations from the calculated values are considerably greater. Only when the differences are above 30 per cent in the observed mid capacity and over 40 per cent in the residual air may they be interpreted as beyond the normal limits of variability.

In the cases of the total pulmonary capacity and vital capacity, it seems that significant pathological deviations consist mainly in finding low volumes (as compared with the calculated values). A considerable increase in the total volume may, however, occasionally be observed during asthmatic attacks and less frequently and also to a much less marked extent in cases of pulmonary emphysema with a history of severe asthma.

The interpretation of the changes found in the volumes of mid capacity and residual air present a more difficult problem. From the observations of other investigators and from our own in cases of chronic pulmonary disease and in cardiac decompensation, it seems that the pathological deviations consist chiefly in increases. Theoretically, we may conceive of cases in which, without the development of emphysema, the alveolar space is encroached upon so severely by the presence of pathological tissue or fluid that a considerable reduction in the amount of air results. One of us (4) has shown that natives at high altitudes, fully adapted to the low oxygen tension, exhibit large emphysematous chests. Although no measurements have been made, we may infer that their lungs would show large mid capac- 

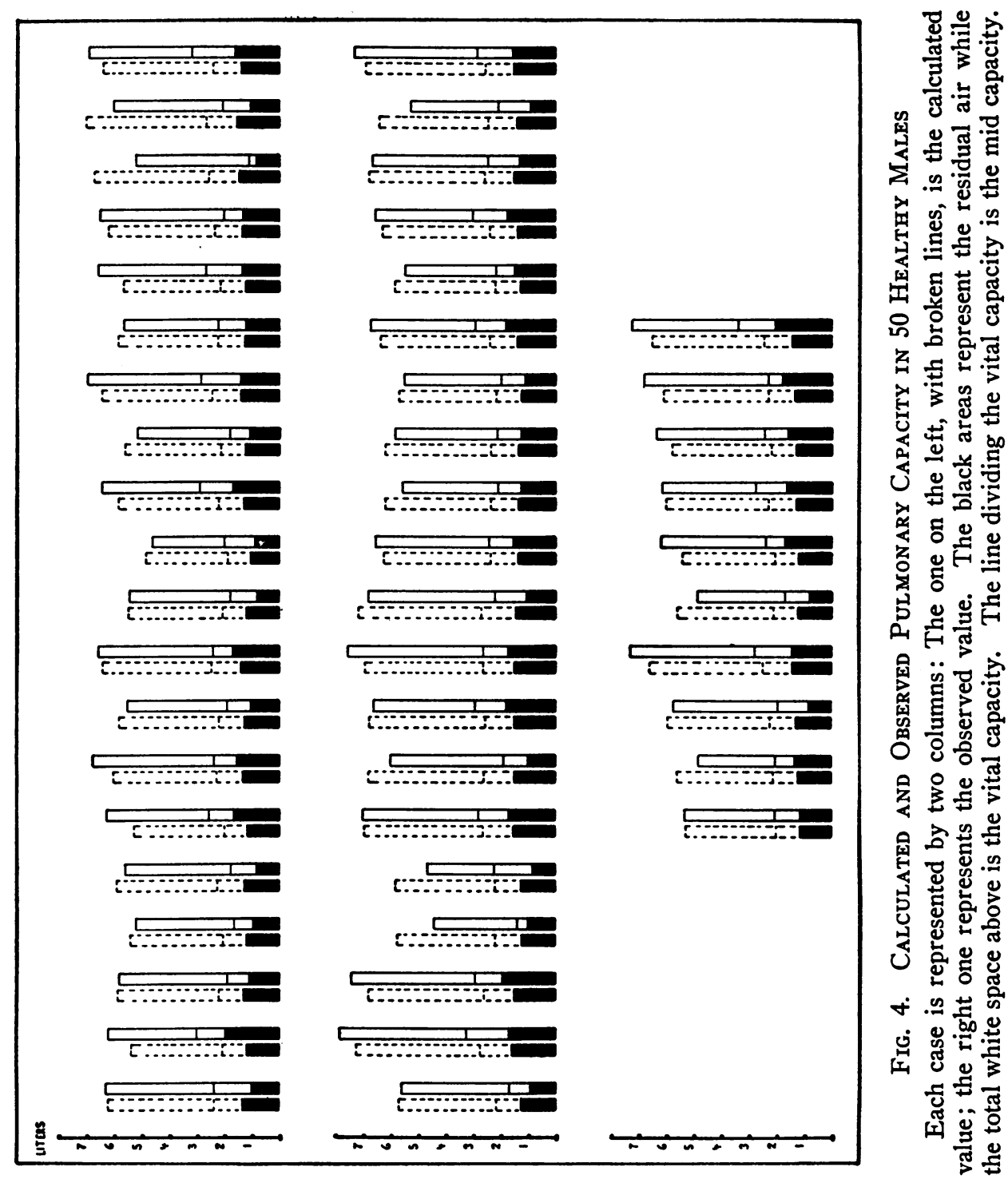
ities and residual volumes. Considering their almost perfect adaptation to the demand for increased ventilation at low oxygen tension, such findings are not to be regarded as pathological. These changes, if accompanied by a corresponding increase in vital capacity (as is the case in natives of high altitudes), represent a beneficial adjustment by means of which a larger area of contact results between the blood flowing through the pulmonary capillaries and the alveolar air. Many years ago Bohr (3) considered an increase in the mid capacity as evidence of a favorable adaptation to the increased demands of ventilation during physical activity.

In the interpretation of moderate changes in the vital capacity, mid capacity and residual volumes, a consideration of their relative values is of fundamental importance. If, for instance, the residual air is increased, we must ascertain whether its increase has been sufficient to produce an abnormal ratio to the total volume of the lungs. If this is the case, it is probably significant.

\section{CHEST EXPANSION AND PULMONARY CAPACITY}

Although in all our cases a considerable number of observations have been made on the degree of chest expansion, different phases of the respiration, as determined by means of external and radiological measurements of the chest, most of the data obtained have been omitted from this discussion because of the wide range of variations. The more important observations have been summarized in Table II. It is evident that the chest expansion, as measured externally in terms of the circumference, and its lateral and

TABLE II

Measurements on chest expansion

\begin{tabular}{|c|c|c|c|c|}
\hline & \multicolumn{4}{|c|}{ External measurements } \\
\hline & Mean & $\begin{array}{l}\text { Standard } \\
\text { deviation }\end{array}$ & $\begin{array}{l}\text { Coefficient } \\
\text { of variation }\end{array}$ & Variations \\
\hline $\begin{array}{l}\text { Circumference expansion, } \mathrm{cm} \ldots \ldots \ldots \ldots \\
\text { Lateral expansion, } \mathrm{cm} . \ldots \ldots \ldots \ldots \ldots \\
\text { Arteroposterior expansion, } \mathrm{cm} \ldots \ldots \ldots \ldots\end{array}$ & $\begin{array}{l}9.1 \pm 0.17 * \\
3.8 \pm 0.07 \\
3.9 \pm 0.08\end{array}$ & $\begin{array}{l}1.8 \pm 0.12^{*} \\
0.7 \pm 0.05 \\
0.8 \pm 0.05\end{array}$ & $\begin{array}{c}\text { per cent } \\
19.7 \\
18.4 \\
20.5\end{array}$ & $\begin{array}{r}4.5-14 \\
2-4.5 \\
1.5-5.5\end{array}$ \\
\hline
\end{tabular}

Radiological Measurements

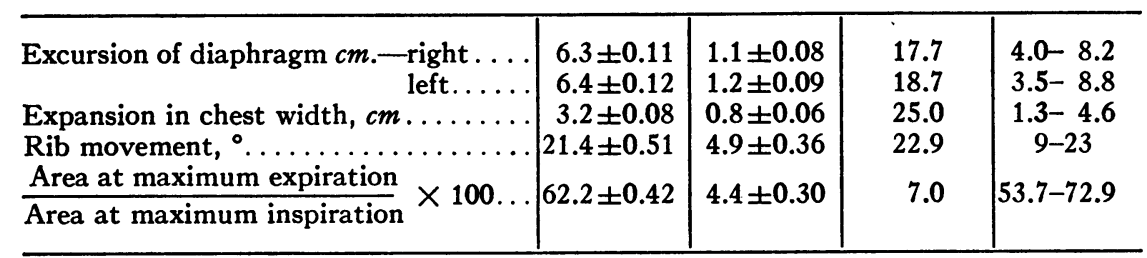

* Probable error. 
anteroposterior diameters vary widely; it is impossible, therefore, in a given case to justify the use of these measurements. It may be said in a general way that a circumferential expansion of less than $6 \mathrm{~cm}$. is to be considered as reduced. No correlation could be found between pulmonary capacity and chest expansion determined by external measurements.

If, on the other hand, we measure from radiological films the areas of the lung fields at maximum expiration and inspiration the relation between the two varies within definite limits. The ratio: (Area at maximum expiration/Area at maximum inspiration) $\times 100$ has, in our series, a mean value of 62.2, with a total deviation from the mean of less than 15 per cent. It appears that this ratio may, therefore, be used as a means of appreciating the degree of chest expansion. If it is higher than 72.0, we may suspect that a definite reduction in excursion has taken place. This ratio it must be remembered, although it takes into consideration the diaphragmatic and lateral expansion of the chest, neglects expansion in the anteroposterior diameter. But since, as we have found, the mean values of the lateral and anteroposterior chest expansion are practically the same, the error will be more or less constant. As a matter of fact, we have found, in a group of cases of chronic pulmonary disease, this similarity of expansion in the two planes.

The ratio (Area at maximum expiration/Area at maximum inspiration) $\times 100$ is higher in people with a long narrow chest, and is chiefly altered by changes in the diaphragmatic excursion. It is interesting to find a relationship between this ratio and the relative values of the pulmonary capacity. In this series of normal cases the correlation coefficient between the ratios: (Area at maximum expiration/Area at maximum inspiration) $\times 100$ and (Residual air/Total volume) $\times 100$ is significant $:+0.4015$ \pm 0.0796 , indicating that alterations in one ratio tend to be accompanied by similar and proportional changes in the other. We will show in another communication that this relationship is considerably more evident in pathological cases in which, when expansion is diminished, the residual air is high. This relationship between chest expansion and relative pulmonary capacity suggests that correction of the latter is necessary if expansion is diminished. A consequence of correcting such a value may be the neglect of a pathological factor, so that a value significantly altered in fact may appear to be normal. It will be more helpful to have both ratios for the proper interpretation of a case, rather than to modify one by means of the other.

Additional information concerning chest expansion may be obtained from a study of other measurements taken from the same radiological film. The diaphragmatic excursion, the lateral expansion of the chest, and the degree of movement of the rib, although showing considerable normal variations, may be considered reduced when they move less than $4 \mathrm{~cm} ., 2 \mathrm{~cm}$. and $12^{\circ}$ respectively. 


\section{SHAPE OF THE CHEST AND LUNG VOLUME}

In all of our 50 cases, two different indices have been calculated to determine the relationship between the shape of the chest and changes in pulmonary capacity and chest expansion. The index: (Depth/Width) $\times 100$ will indicate whether the chest is of the rounded or flat type. There are wide variations in this index, from 58 to 84 with a mean value of 68.5 (Table III). In comparing this index with the different absolute and rela-

TABLE III

Shape of the chest

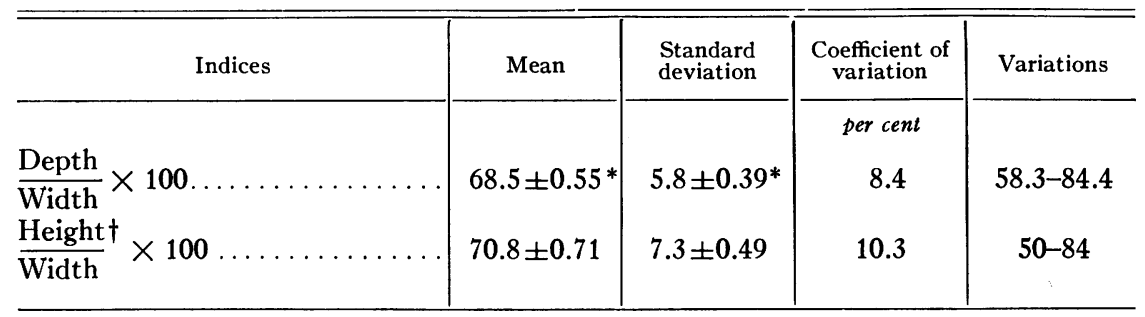

* Probable error.

+ This measurement represents the average height of both sides of the diaphragm (at mid capacity) as determined on the radiological films.

tive volumes, we have not found a significant correlation to indicate that variations in the pulmonary capacity may be attributed to this factor. There was no correlation, either, between this index and the degree of chest expansion, except that the movement of the ribs is less marked when the chest index is high, that is to say in rounded chests.

The index: (Height/Width) $\times 100$ (both diameters being measured on $\mathrm{x}$-ray films taken at mid capacity distinguishes two types of chest: broad, muscular ones with a high diaphragm (hypersthenic type), and slender and long, narrow ones with a low diaphragm (asthenic type). In the former, the index is low and in the latter high. We have found that the shape or type of the chest from this point of view has a definite influence upon the pulmonary capacity, and that this is reflected chiefly in changes in the volume of reserve air. In our series of normal males, it was not an uncommon observation to find a rather low vital capacity (as compared with the calculated value) in the hypersthenic type of individual, due to the small volume of reserve air. The correlation coefficient between the index: (Height/Width) $\times 100$ and the reserve air was +0.4133 \pm 0.0803 , which is significant. In the three cases in which the lowest indices were obtained $(50,52$, and 58$)$ the observed reserve air was 0.26 , 0.50 and 0.38 liters respectively.

The radiological chest volume was considerably larger in those individuals with long narrow chests and low diaphragms. They exhibited correspondingly the highest total pulmonary capacity. This fact stands in 


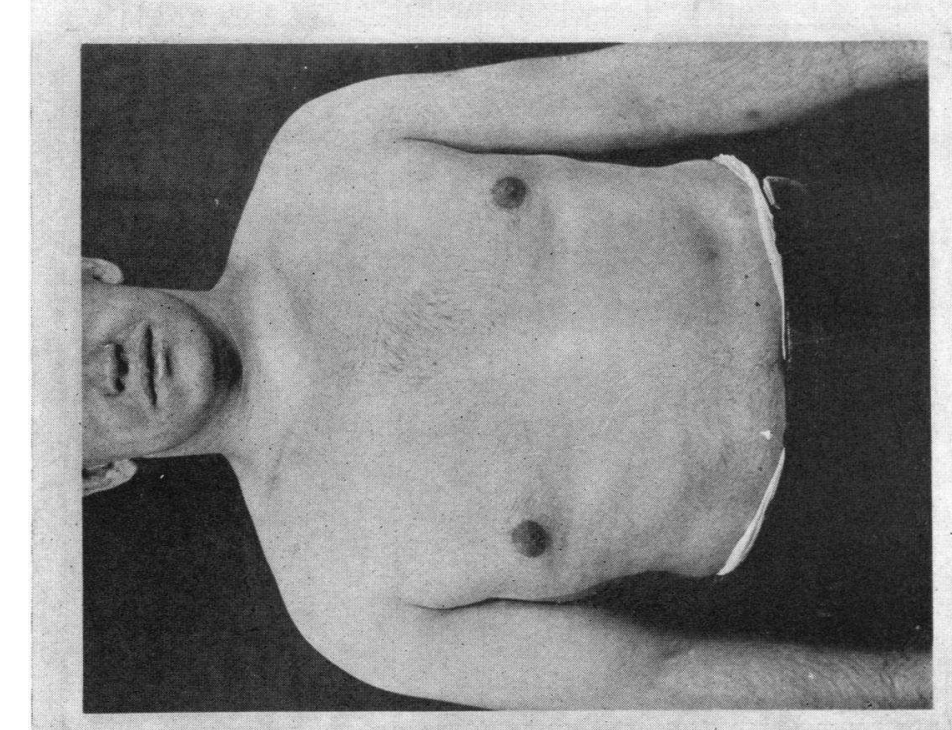

委
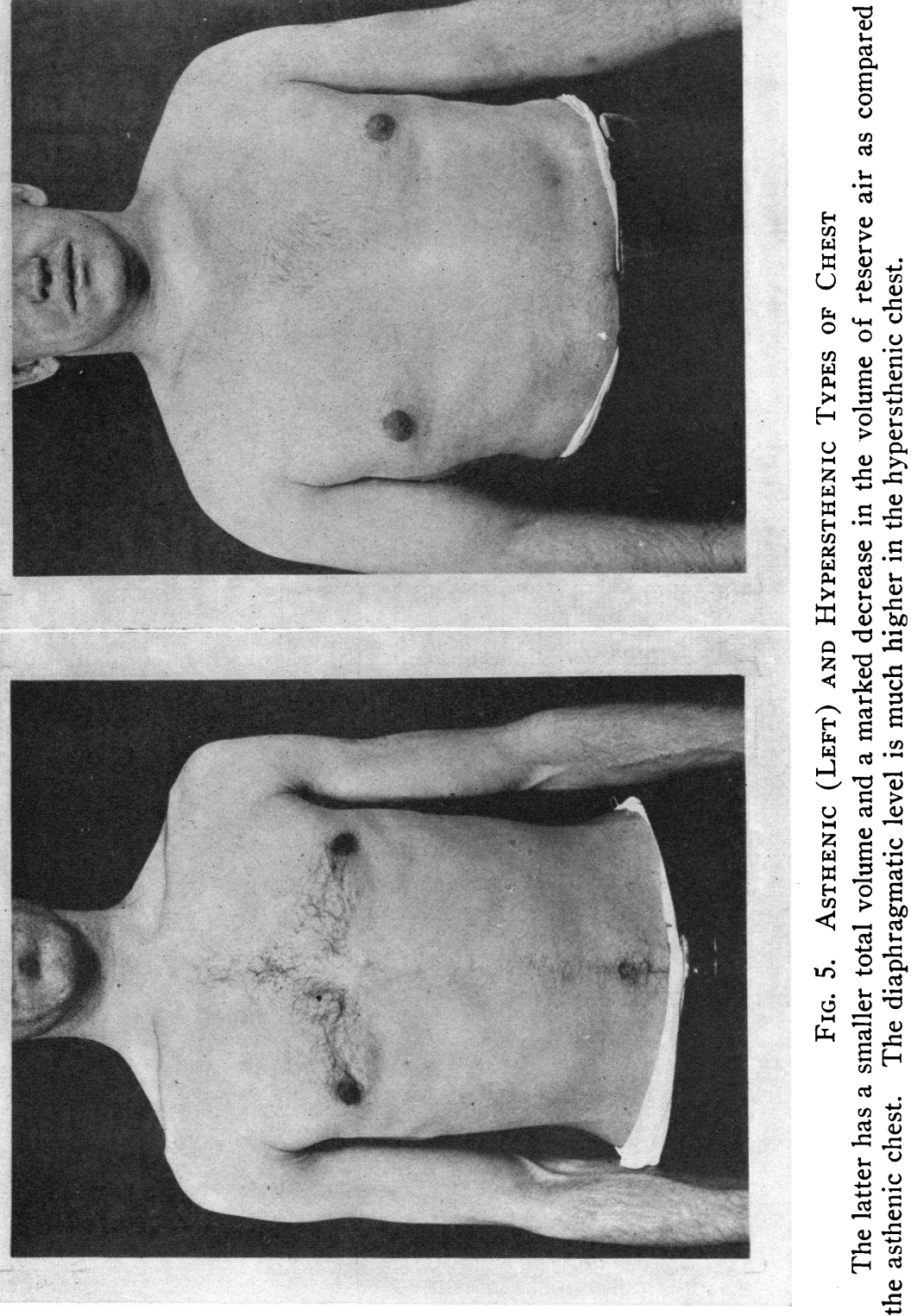
sharp contrast with what one might judge clinically, because men with broad, muscular and apparently big chest cavities are regarded as having greater pulmonary volumes compared with the other type. The reverse is, however, the case, indicating the importance of taking into consideration the diaphragmatic level in calculating the pulmonary capacity in a given case.

Comparing the chest expansion in hypersthenic individuals (broad muscular chests with high diaphragms) we did not find any significant relationship between this and the ratio: (Area at maximum expiration/Area at maximum inspiration) $\times 100$ and the diaphragmatic excursion. There was, however, almost no lateral expansion of the chest during the determination of the reserve air (a forced expiration from the mid capacity level) in contrast with other cases in which an appreciable expansion was noticed and measured.

\section{SUMMARY AND CONCLUSIONS}

In a preceding paper (5) have been presented the values of pulmonary capacity found in observations made on 50 healthy males. In the present communication we have discussed the correlation between the total capacity and its main subdivisions with height, weight, surface area and external and radiological measurements of the thorax. It has been shown that they may be best calculated in a given case from the so-called " radiological chest volume." The method of calculation has been fully presented ; comparison of the observed and the calculated volumes shows a very close correspondence. The application of these observations permits one to appreciate pathological deviations.

Studies have been made of the normal variability in the degree of expansion of the chest, which is best exhibited in measurements of the chest film, taken by means of a standard, the technique which has been described. The same film, together with the measurement of the anteroposterior diameter of the chest at maximum inspiration, furnishes all necessary information for the calculation of a given pulmonary capacity if correlation coefficients and regression formulae are used.

The influence of the shape of the chest on the pulmonary capacity and on the degree of expansion of the chest has also been investigated.

The observations presented lead to the following conclusions:

1. When the total pulmonary capacity and its main subdivisions are calculated on the basis of the " radiological chest volume," at maximum inspiration, the following deviations in the observed values (as compared with the calculated ones) are considered to be significant: a difference of over 15 per cent in the total pulmonary capacity and vital capacity; and of 30 per cent and 40 per cent in the mid capacity and residual air respectively.

2. If the ratio: (Area at maximum expiration/Area at maximum inspiration $) \times 100$ is higher than 72.0 , a reduction in chest expansion is 
indicated. Further evidence of deficient expansion is obtained if the diaphragmatic excursion, the lateral expansion and the degree of movement of the rib are found to be less than $4 \mathrm{~cm} ., 2 \mathrm{~cm}$. and $12^{\circ}$ respectively.

3. There is a certain correlation between the degree of chest expansion (as appreciated by the ratio mentioned) and the relative proportions of subdivisions of the pulmonary capacity. Deficient expansion tends to be accompanied by a higher percentage of the residual air in relation to the total capacity.

4. There is a relationship between the shape of the chest and the capacity of the lungs. Individuals with broad, muscular chests and high diaphragms (hypersthenic type) usually present low volumes of reserve air, as compared with long and narrow-chested individuals with low diaphragms (asthenic type). The latter have larger thoracic capacity and consequently larger pulmonary capacity.

5. From the observations made on normal males, it is possible to detect pathological changes in the absolute and relative pulmonary capacity in a given case. The importance of recognizing such alterations is obvious.

\section{BIBLIOGRAPHY}

1. Binger, C. A. L., J. Exper. Med., 1923, xxxviii, 445. The Lung Volume in Heart Disease.

2. Binger, C. A. L., and Brow, G. R., J. Exper. Med., 1924, xxxix, 677. Studies on the Respiratory Mechanism in Lobar Pneumonia. A Study of Lung Volume in Relation to the Clinical Course of the Disease.

3. Bohr, C., Deutsches Arch. f. klin. Med., 1907, 1xxxviii, 385. Die funktionellen Änderungen inder Mittellage und Vitalkapazität der Lungen.

4. Hurtado, A., Am. J. Phys. Anthropol., 1932, xvii, 137. Respiratory Adaptation in the Indian Natives of the Peruvian Andes. Studies at High Altitude.

5 Hurtado, A., and Boller, C., J. Clin. Invest., 1933, xii, . Studies of Pulmonary Capacity and its Subdivisions. I. Normal, Absolute and Relative Values.

6. Lundsgaard, C., and Schierbeck, K., Proc. Soc. Exper. Biol. and Med., 1922-23, xx, 160. Studies on Lung Volume. VII. Relation of Size of Chest to Lung Volume.

7. Lundsgaard, C., and Van Slyke, D. D., J. Exper. Med., 1918, xxvii, 65. Studies of Lung Volume. I. Relation between Thorax Size and Lung Volume in Normal Adults.

8. Thomas, H., Am. J. Roentgenol., 1931, xxvi, 878. A Graphic Method of Recording the Respiratory Excursion of the Diaphragm.

9. West, H. F., Arch. Int. Med., 1920, xxv, 306. Clinical Studies on the Respiration. VI. A Comparison of Various Standards for the Normal Vital Capacity of the Lungs. 